\title{
Characterization of HIV-1 RNA forms in the plasma of patients undergoing successful HAART
}

\author{
Carlos A. Lopez $\cdot$ Manuel Vazquez $\cdot$ Martin D. Hill • \\ Maria Del C. Colon - Tirtsa Porrata-Doria • \\ Ian C. D. Johnston · Eric Lorenzo
}

Received: 9 November 2009/ Accepted: 10 March 2010/Published online: 23 April 2010

(C) The Author(s) 2010. This article is published with open access at Springerlink.com

\begin{abstract}
An assay to characterize plasma human immunodeficiency virus 1 (HIV-1) sequences for patients with low viral loads was developed by combining the selective binding of anti-CD44 MicroBeads with a nested RT-PCR targeting the env C2V4 region. Sequences were obtained from 10 of $20 \mathrm{HIV}+$ patients who had viral loads below 48 copies $/ \mathrm{ml}$. Sequences derived from plasma were compared to those from CD14+ CD16 + monocytes and $\mathrm{CD} 4+\mathrm{T}$ cells. The plasma sequences were most closely related to those amplified from monocytes, suggesting that during successful antiretroviral therapy, the predominant plasma virus originates from myeloid cells. By characterizing HIV-1 RNA sequences from $8 \mathrm{ml}$ of plasma while avoiding multiple steps, which can lead to contamination and deterioration, this method can help elucidate the viral forms in patients with therapeutically suppressed HIV-1. Understanding the source of residual viremia is crucial in developing approaches for viral eradication.
\end{abstract}

C. A. Lopez - M. Vazquez - M. D. Hill - M. Del C. Colon ·

T. Porrata-Doria $\cdot$ E. Lorenzo $(\bowtie)$

Molecular Virology Laboratory, Department of Physiology

and Pharmacology, Ponce School of Medicine, P.O. Box 7004,

Ponce, PR 00732, USA

e-mail: lorenzoe@niaid.nih.gov

M. D. Hill

e-mail: mhill@psm.edu

I. C. D. Johnston

Miltenyi Biotec GmbH, Friedrich-Ebert-Str. 68,

51429 Bergisch Gladbach, Germany

Present Address:

E. Lorenzo

Scientific Review Program, AIDS Research Review Branch,

NIAID, Division of Extramural Activities (DEA),

6700B Rockledge Dr., Room 3134, Bethesda,

MD 20892-7616, USA

\section{Introduction}

The causative agent of the acquired immunodeficiency syndrome (AIDS) belongs to the family Retroviridae, subfamily Orthoretrovirinae, genus Lentivirus, species Human immunodeficiency virus 1 (HIV-1). HIV-1 maintains a residual viremia even when suppressed by a highly active antiretroviral therapy (HAART) regimen to below the clinical detection limits (commonly designated as being a viral load of $<50$ copies $/ \mathrm{ml}$ ). If therapy becomes ineffective or is discontinued, a small number of latently-infected cells can lead to viral rebound [1-7]. The dynamics and the source of this persistency have only been partly clarified. Probably the most accepted mechanism of persistence is the existence of viral reservoirs in latent and stably infected CD4+ T cells [8-10]. Cryptic viral replication may also continue in immunologically and pharmacologically restricted sites, such as the brain and testes [7]. This persistence represents a significant challenge for the development of a strategy for viral eradication.

In order to understand the nature of this residual viremia, a major obstacle needs to be overcome: developing a reliable and consistent method to characterize the residual HIV in plasma when viral loads are low and below the limits of quantitation. Previous studies have shown that obtaining sequences for analysis is challenging because of the extremely low concentration of plasma HIV RNA in patients under suppressive HAART [11-19]. In cases where plasma clone sequences have been successfully obtained and characterized, the findings can help elucidate viral dynamics under HAART suppression [18, 20-22]. One of the obstacles identified is the diversity of the virus [23] resulting in primer mismatch and poor RT-PCR amplification.

Ultracentrifugation followed by RT-PCR amplification has often been used to obtain these sequences, but these 
methods need large volumes of plasma, and the extended process results in deterioration of the viral material. It has been demonstrated that the elimination of the pre-extraction ultracentrifugation step improved nucleic acid yield and purity to allow genotyping [24]. This study describes a technique that involves reduced processing time, simple isolation and a modest volume of plasma $(8 \mathrm{ml})$. This was achieved by combining the techniques of specific magnetic isolation of HIV virions and amplification with primers targeting a stable region in the viral RNA sequence directly in a viral lysate. No RNA purification step was necessary. The utility of this technique was tested by examining the cellular source of the low-level viremia in two patients.

Our isolation protocol employs magnetic labeling using the binding of anti-CD44 MicroBeads ( $\mu$ MACS VitalVirus HIV Isolation Kit, Miltenyi Biotec, Germany). The budding virion incorporates cell membrane markers into its envelope [25], which can be used as a means of binding virions for collection and concentration [26-29]. CD44 has been shown to colocalise at the site of HIV budding from the cell membrane in $\mathrm{T}$ cell and monocyte cell lines [30, 31]. These findings have been extended to acutely infected cells and latently-infected cells that were reactivated to induce HIV production [26]. Indeed, CD44 appears to be upregulated following mitogenic HIV reactivation in cell lines [31]. The CD44 molecule may also assist the virus in trafficking to lymphoid tissues [25, 32]. HIV-1 RNA capture efficiency for the $\mu$ MACS CD44 MicroBeads from a variety of patient samples has been shown to average at least 60\% [29], while efficiency of capture from spiked virus/ cell culture supernatants approaches $100 \%$ (unpublished observations). Recently, anti-CD44 MicroBeads have also been shown to increase HIV infectivity in culture dramatically [33].

In the study presented here, the isolated HIV-1 RNA was amplified by polymerase chain reaction (PCR) using a nested approach with primers that target the env gene sequence. Studies have demonstrated that the areas before the V3 region and after the V4 region are relatively conserved and homogeneous both within a patient sample and between patients $[34,35]$. At the same time, the sequences within the $\mathrm{C} 2 \mathrm{~V} 4$ region undergo rapid diversification, making this area useful for phylogenetic reconstructions of viral evolution [36-40]. Furthermore, the elucidating sequences from the $\mathrm{C} 2 \mathrm{~V} 4$ region can help determine tropism and immune escape.

\section{Materials and methods}

Study subjects

Twenty HIV-positive men and women receiving a successful HAART regimen (suppressed viremia to
$<48$ copies/ml for at least 1 year) were enrolled from two immunological clinics in Puerto Rico and donated blood for this study. Demographic data and CD4 counts are presented in Table 1. Samples were processed within $2 \mathrm{~h}$ of collection. The plasma was separated from the cellular components by centrifuging blood at 3,500 rpm for $15 \mathrm{~min}$. Plasma HIV-1 viral loads were determined by clinical ultrasensitive Amplicor HIV-1 Monitor Test (quantification limit, $<48$ copies/ml, Roche Diagnostics Systems), and the viral load in all patients was below the limits of quantification. Due to the sensitivity of this quantitation assay, "below detection" refers to samples containing $<48$ virions $/ \mathrm{ml}$.

\section{HIV-1 plasma RNA isolation}

HIV-1 RNA was isolated from plasma using a modified version of the $\mu$ MACS VitalVirus HIV Isolation Kit (Miltenyi Biotec $\mathrm{GmbH}$, Germany). The reagents used in this protocol were those contained in the kit, including the anti-CD44 MicroBeads, the equilibration buffer (EqB) and the viral wash buffer (VWB). HIV-1 virions present in the patient plasma were magnetically labeled by mixing $200 \mu \mathrm{l}$ of anti-CD44 MicroBeads and $8 \mathrm{ml}$ of plasma in a $15-\mathrm{ml}$ conical tube and incubating for $1 \mathrm{~h}$ at room temperature. The sample was centrifuged at $5,000 \mathrm{~g}$ for $1 \mathrm{~min}$ to consolidate any plasma remaining in the lid and the walls of the tube. A MACS $\mu$ Column (included in the kit) was

Table 1 Patient demographics and health

\begin{tabular}{|c|c|c|c|}
\hline Patient ID & Sex/age & $\begin{array}{l}\text { CD4 count } \\
\left(\text { per } \mathrm{mm}^{3}\right)\end{array}$ & $\begin{array}{l}\text { Months since } \\
\text { diagnosis }\end{array}$ \\
\hline 1 & $F / 36$ & 988 & 156 \\
\hline 2 & $\mathrm{~F} / 41$ & 505 & 132 \\
\hline 3 & $\mathrm{~F} / 42$ & 650 & 192 \\
\hline 4 & $\mathrm{~F} / 46$ & 504 & 168 \\
\hline 5 & $\mathrm{~F} / 57$ & 845 & 204 \\
\hline 6 & $\mathrm{M} / 51$ & 347 & 204 \\
\hline 7 & $\mathrm{M} / 39$ & 439 & 132 \\
\hline 8 & $\mathrm{M} / 23$ & 500 & 36 \\
\hline 9 & $\mathrm{M} / 47$ & 769 & 120 \\
\hline 10 & $\mathrm{~F} / 47$ & 348 & 168 \\
\hline 11 & $\mathrm{~F} / 39$ & 616 & 120 \\
\hline 12 & $\mathrm{M} / 50$ & 512 & 216 \\
\hline 13 & $\mathrm{M} / 67$ & 560 & 192 \\
\hline 14 & $\mathrm{M} / 42$ & 758 & 144 \\
\hline 15 & $\mathrm{~F} / 44$ & 397 & 180 \\
\hline 16 & $\mathrm{M} / 56$ & 175 & 192 \\
\hline 17 & $\mathrm{M} / 32$ & 410 & 96 \\
\hline 18 & $\mathrm{M} / 46$ & 710 & 156 \\
\hline 19 & $\mathrm{M} / 52$ & 339 & 180 \\
\hline 20 & $\mathrm{~F} / 47$ & 638 & 108 \\
\hline
\end{tabular}


placed in the $\mu \mathrm{MACS}$ separator, equilibrated with $100 \mu \mathrm{l}$ EqB and washed three times with $100 \mu \mathrm{l}$ VWB containing $0.5 \%$ BSA. The plasma containing the labeled virions was added to the $\mu$ Column $1-\mathrm{ml}$ at a time. The column was washed twice with $200 \mu \mathrm{l} \mathrm{VWB}$, removed from the magnetic stand and placed above a $1.5-\mathrm{ml}$ microtube. The magnetically labeled virions were lysed within the column, and viral RNA contained in the viral lysate was eluted in two steps. First, $100 \mu \mathrm{l}$ of lysis buffer (50 mM Tris, $\mathrm{pH} 8.4$, $0.5 \%$ Igepal) were added and incubated for $1 \mathrm{~min}$. Then, another $100-\mu l$ aliquot of lysis buffer was added, and using a 5-ml syringe plunger, pressure was applied to the column to elute the entire sample. The eluate was immediately placed at $-20^{\circ}$ to preserve the isolated plasma HIV-1 RNA.

\section{Cell isolation}

Peripheral blood mononuclear cells (PBMC) were separated from the other cell components by density gradient sedimentation on Histopaque-1077 (Sigma-Aldrich, St. Louis, MO). CD14+ CD16+ monocytes were separated from fresh PBMC by using a combination of CD14 and CD16 monoclonal antibodies (BD Biosciences, San Jose, $\mathrm{CA}$ ), and $\mathrm{CD} 4+\mathrm{T}$ cells were separated using $\mathrm{CD} 3$ and CD4 monoclonal antibodies (BD Biosciences). The cells were sorted in a FACST Calibur Aria (BD Biosciences). Based on flow cytometry, the isolated monocyte and T cell suspensions yielded average purities of 95 and $98 \%$, respectively, using FACSCalibur and CellQuest software (BD Biosciences). Genomic DNA was isolated from monocytes and CD4+ T cells using a QIAmp DNA Micro Kit (QIAGEN, Inc, Valencia, CA).

\section{Nested RT-PCR HIV-1 env RNA amplification}

The isolated HIV-1 env RNA was amplified by reverse transcriptase polymerase chain reaction (RT-PCR) using a OneStep RT-PCR Kit and HotStar Taq DNA Polymerase (QIAGEN, Inc). An RNA template volume of $40 \mu \mathrm{l}$ was used for the primary reaction. The $\mathrm{C} 2 \mathrm{~V} 4$ region amplification was performed with the primers ED31 (forward) and
ED12 (reverse) (Table 2) [39]. The conditions of the primary phase (RT-PCR) were 1 cycle of $50^{\circ}$ for $30 \mathrm{~min}, 95^{\circ}$ for $16 \mathrm{~min}, 60^{\circ}$ or $58^{\circ}$ for $1 \mathrm{~min}$, and $72^{\circ}$ for $2.5 \mathrm{~min} ; 35$ cycles of $95^{\circ}$ for $30 \mathrm{~s}, 60^{\circ}$ or $58^{\circ}$ for $45 \mathrm{~s}$ and $72^{\circ}$ for $1 \mathrm{~min}$; 1 cycle of $72^{\circ}$ for $10 \mathrm{~min}$ and hold at $4^{\circ}$. For the second phase (PCR), $1 \mu \mathrm{l}$ of product was used along with CV3 (forward and reverse) primers (Table 2) [39]. The conditions for the secondary-phase nested PCR were 1 cycle of $95^{\circ}$ for $15 \mathrm{~min}, 51^{\circ}, 49^{\circ}$ or $45^{\circ}$ for $1 \mathrm{~min}$ and $72^{\circ}$ for $2.5 \mathrm{~min}$; 35 cycles of $94^{\circ}$ for $30 \mathrm{~s}, 51^{\circ}, 49^{\circ}$ or $45^{\circ}$ for $45 \mathrm{~s}$ and $72^{\circ}$ for $1 \mathrm{~min} ; 1$ cycle of $72^{\circ}$ for $10 \mathrm{~min}$ and hold at $4^{\circ}$. The resulting amplicon (525 bp) was electrophoresed along with a low-molecular-weight marker in $1.2 \%$ agarose and stained with ethidium bromide. To minimize the PCR error rate, a single positive PCR was used to generate multiple clones for sequencing.

\section{Cloning and sequencing of $\mathrm{C} 2 \mathrm{~V} 4$}

PCR products were cloned into the pCR 2.1 vector (Invitrogen, Carlsbad, CA) using the TOPO TA Cloning Kit (Invitrogen, Carlsbad, CA) according to the manufacturer's specifications. The recombinant vector was introduced into One Shot Chemically Competent E. coli (Invitrogen Corp) and amplified, and the plasmid DNA was purified using a QIAprep Spin Miniprep Kit (QIAGEN, Inc). M13 plasmid primers [41] were used to sequence the clones in an Applied Biosystems 3130xl Genetic Analyzer (Applied Biosystems, Foster City, CA).

\section{Analysis of sequences}

Alignment of the nucleotide sequences was conducted using the CLUSTAL W application [42, 43] integrated in the BioEdit version 7.0.5.2 [44] and then edited by hand. The pairwise nucleotide distance calculations for plasmaderived sequences were performed using MEGA 4 [45] employing the Kimura 2-parameter method [46]. For the intrapatient analysis of sequences derived from plasma, CD14+ CD16+ monocytes and CD4+ T cells, the pairwise distance calculations were performed as described above but by using the Maximum Composite Likelihood

Table 2 Primer sequences and gene location

\begin{tabular}{lll}
\hline Primer ID & Sequence 5'-3' & Genome location \\
\hline ED31 & CCTCAGTCATTACACCAGGCCTGTCCAAAG & $6817-6846$ \\
ED12 & AGTGCTTCCTGCTGCTCCCAAGAACCCAAG & $7782-7811$ \\
CV3-F & CTGTTAAATGG CAGTCTAGC & $7002-7021$ \\
CV3-R & TGATGGGAGGGGTATACATT & $7523-7542$ \\
\hline
\end{tabular}

Primers used in the nested RT-PCR for the amplification of the env gene C2V4 region. The gene location is based on the HIV-1 HXB2 genome. (GenBank accession number K03455) [49] 
substitution model. MEGA 4 was also used to create a phylogenetic tree of 1,000 bootstrapped data sets [47], which was constructed by the neighbor-joining method [48], assuming a transition/transversion rate of 2.0. The C2V4 segment of the reference sequence HIV-1 HXB2 (GenBank accession number K03455) [49] was used as an outgroup (gene location 7002-7400). A position-specific scoring matrix was used to analyze the genetic tropism of the plasma-derived HIV-1 V3 region sequences (WebPSSM) [50].

\section{Results}

Method performance

Duplicate sample volumes of $8 \mathrm{ml}$ per patient were run under identical conditions. Envelope sequences from 10 out of 20 patients were successfully characterized, representing a success rate of $50 \%$. Details of the patient samples are listed in Table 3, including detectability of viral RNA and success of viral genotyping.

To better assess the sensitivity of the test, the samples were divided in two groups. Group A samples were classified as "below 48 copies/ml" for those with an observable amplification of virus during quantitation and Group B were classified as "nondetected" for those for whom no amplification was detected. In Group A, HIV-1 plasma RNA from 5 out of 8 samples $(62.5 \%)$ could be characterized, while in Group B, characterization was successful in 5 out of 12 samples $(41.7 \%$ ) (Table 3 ).

Evolutionary history reconstruction

Evolutionary history of the HIV-1 viral forms from the characterized plasma samples was inferred using the phylogeny of env gene sequences. The inferred phylogenetic tree (Fig. 1) showed that the plasma sequences from all patients clustered separately with $100 \%$ bootstrap values. This finding greatly diminishes the possibility of laboratory contamination.

Phylogenetic analysis of the characterized HIV-1 RNA sequences

The existence of different quasispecies within the same patient is a well-recognized characteristic of HIV-1 [51]. The intrapatient analysis showed a genetic variability with nucleotide distances between $0-4.2 \%$, which is consistent with a homogeneous infection or could represent resampling among patients with few target virions. In contrast, the interpatient analysis presented high variability between all patients (10-20\%). The divergent nucleotide distances are also consistent with separate sources for the viral forms from each patient and speak against contamination.

An analysis of predicted tropism was performed using the sequences from the plasma virions. Five of these patients had CCR5 viruses, three had CXCR4, and the other two had both forms. Disabling mutations, either frameshifts or stop codons, appeared in at least one clone from two patients.

Analysis of intrapatient sequences from plasma, CD14+ CD16+ monocytes and CD4+ T cells

A small pilot project was undertaken in order to test the utility of the assay. The assay was employed to examine the sources of residual viremia in two patients, numbers 5 and 6 . In addition to the characterization of circulating plasma virus, integrated provirus sequences were analyzed from two blood cell populations: CD4+ T cells and CD14+ CD16+ monocytes. CD14+ CD16+ are a minority set of monocytes that have been shown to express the HIV coreceptor CCR5 at a high level [52]. The phylogenetic reconstruction was

Table 3 Quantitation and characterization of patient plasma samples

\begin{tabular}{llllll}
\hline Sample ID & Viral quantity (copies/ml) & Characterized? & Sample ID & Viral quantity (copies/ml) & Characterized? \\
\hline P1 & ND & No & P11 & $<48$ & Yes \\
P2 & ND & No & P12 & ND & No \\
P3 & Yes & P13 & ND & No \\
P4 & Yes & Yes & P14 & ND & Yes \\
P5 & ND & Yes & P15 & ND & Yes \\
P6 & $<48$ & Po & P16 & $<48$ & Yes \\
P7 & $<48$ & No & P18 & ND & Yes \\
P8 & $<48$ & No & P19 & $<48$ & No \\
P9 & ND & No & P20 & ND & Yes \\
P10 & ND & N &
\end{tabular}

Samples characterized and not characterized are shown with their respective viral quantitation results

$P$ patient, ND HIV-1 RNA not detected, $<48$ less than 48 HIV-1 RNA copies per milliliter of plasma 


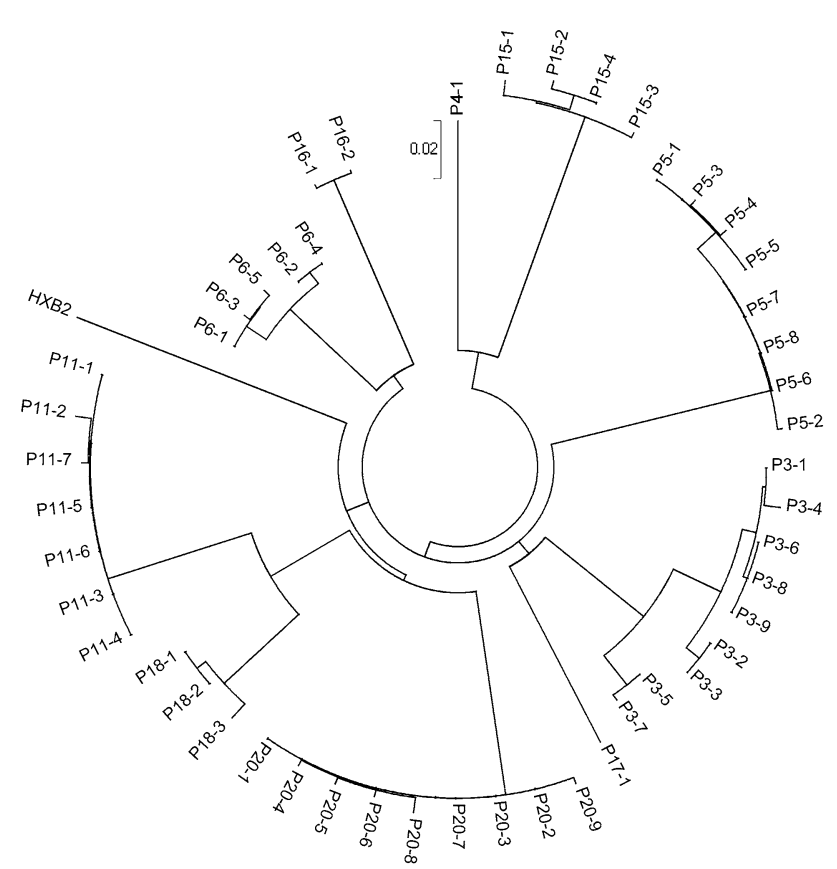

Fig. 1 Phylogenetic reconstruction for the assay performance assessment. The evolutionary history of the validation sequences was reconstructed in a phylogenetic tree. Neighbor joining was used with the Kimura 2-parameter method in 1,000 bootstrapped replications. The HIV-1 HXB2 sequence (gene location 7002-7400) was used as an outgroup (GenBank accession number K03455). The sample ID is represented by the letter $P$ (patient) and a number. The number after the dash corresponds to the clone number. The scale is at a $2 \%$ nucleotide difference

performed as described above, using the maximum composite likelihood substitution model. The inferred phylogenetic tree is presented in Fig. 2.

Pairwise distance calculations showed minimal variability between cloned sequences derived from the same source $(<0.6 \%)$ in both patients. This could have been due to a homogenous infection or resampling from a small pool of virions. The exception was the CD4+ T cells sequences, which showed differences (0-6.2\%) indicating heterogeneous infection. The comparison between sources showed a closer relationship between plasma and CD14+ CD16+ monocytes in both patients. For patient 5, nucleotide differences were observed when comparing plasma versus monocytes (0-1.5\%), plasma versus CD4+ T cells (99.7\%), and monocytes versus CD4+ T cells (8.5-8.7\%). In patient 6 , the observed distances were $0-1.7 \%$ for plasma versus monocytes, $2.9-5.1 \%$ for plasma versus CD4+ T cells, and $2.9-4.3 \%$ for monocytes versus CD4+ T cells.

\section{Discussion}

It is well established that residual HIV-1 viremia can continue after long-term adherence to antiretroviral therapy and the resulting increase in the capacity of the body to defend itself. In this setting, the virus resides in reservoirs of long-lived cells or finds cryptic places to hide, evading therapeutic and immunologic pressures. Few studies have characterized plasma HIV-1 RNA sequences in patients with viral loads below 48 copies/ml [11, 17, 18, 22, 23, 53]. The method presented here has several advantages over other methods. It requires a lower volume of blood than most, it requires less sample processing, it has a comparable rate of success, and it amplifies the C2V4 region of the envelope, an area that is important for determining tropism and tracking viral evolution and immune escape.

The most utilized approach was developed by Bailey and colleagues in 2006 [23]. Their team collected $17 \mathrm{ml}$ of blood per visit during a period of intensive sampling (every 2-3 days for 36 closely spaced visits). A total of $6-8 \mathrm{ml}$ of plasma was filtered and ultracentrifuged at $25,200 \times g$ for $2 \mathrm{~h}$ at $4^{\circ} \mathrm{C}$ to pellet the sample virions. Viral RNA was isolated using the QIAamp Viral RNA Kit (Qiagen) silica membrane binding method, and the protease and $R T$ genes were amplified in seven different RT-PCR reactions. One of the study's difficulties was the necessity for intensive sampling to recover the plasma. Also, they did not amplify the env gene, so tropism studies could not be performed on the characterized sequences.

McClernon et al. [24], using silica columns, were able to obtain sequences from $75 \%$ of samples that had 100 500 virions $/ \mathrm{ml}$, and in one iteration of their method, $30 \%$ success for samples 50-500 virions $/ \mathrm{ml}$. These were with spiked samples of a homogenous viral form, in contrast to our study using diverse virus found in patients. Using a quantifiable viral load, McClernon et al. were able to assess viral recovery rate; we were not.

The goal of this study was to develop an assay that can reliably recover viral material while using less plasma volume and which would allow processing the sample in a shorter period of time. With a $50 \%$ success rate, this study has shown that plasma HIV-1 RNA can be genetically characterized in samples with viral detection values of $<48$ copies/ml while reducing both the sample volume and the process time. The assay tended towards a higher rate of characterization in samples with viral detection values of $<48$ copies/ml (62.5\%) when compared to samples with no detectable HIV-1 RNA (41.7\%).

The isolation of virus by the method described here requires capture using CD44 selection. CD44 is involved in lymphocyte homing, is expressed on many cell types, including both lymphocytes and macrophages [54], and is one of the host molecules most frequently incorporated by the budding HIV-1 [26]. Using CD44 reactivity, recovery of $60 \%$ of HIV-1 in patient samples has been demonstrated 
Fig. 2 Phylogenetic reconstruction of HIV-1 env nucleotide sequences from CD4+ T cells, CD14+ CD16+ monocytes, and plasma isolates of samples P5 and P6.

Evolutionary reconstruction of the plasma-derived HIV-1 env sequence was generated using neighbor joining with the Kimura 2-parameter method. Numbers between branch nodes represent bootstrap values (1,000 replicates). a Patient 5, b patient 6 . Samples are distributed as follows: closed squares monocytes; open triangles CD4+ T cells; open circles plasma; closed diamonds outgroup (HXB2, GenBank accession number K03455). The number of substitutions per site is indicated by the distance bar shown at the bottom

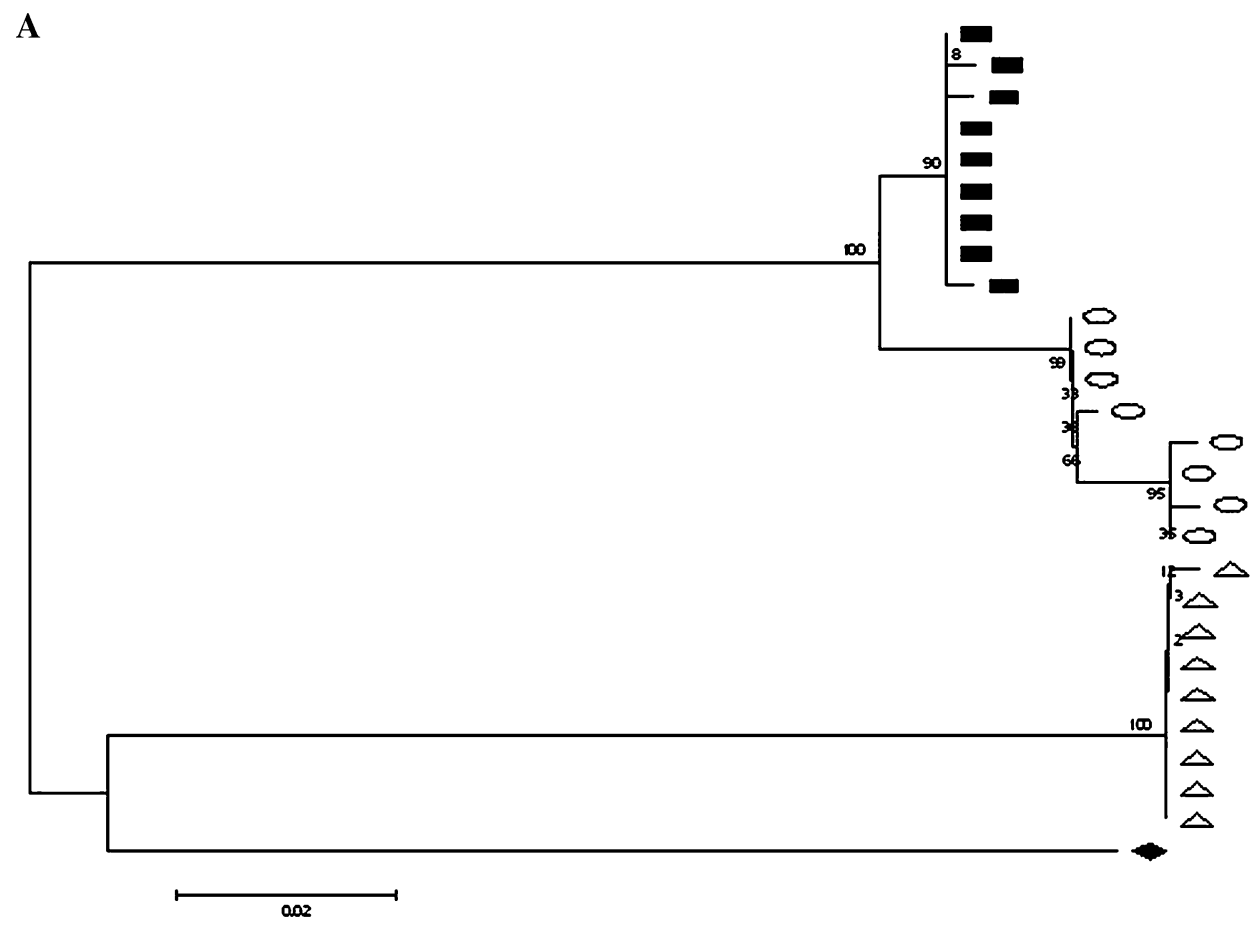

B

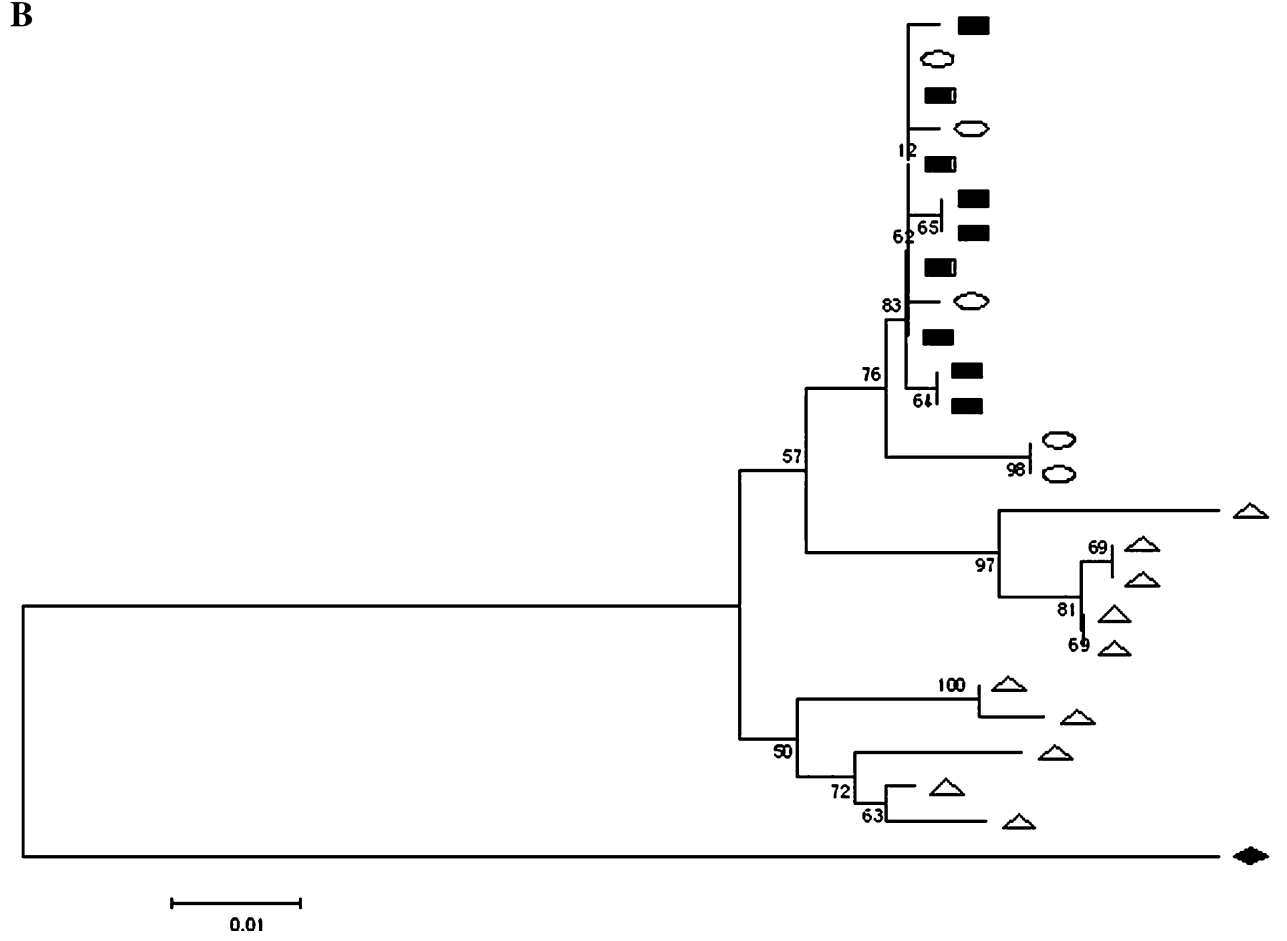

[29]. Nevertheless, this method selects against virions that do not bear CD44.

Other cell-surface markers may be useful in collecting and concentrating the virus; however, the presence of a molecule does not guarantee efficient acquisition. While the capture of HIV by HLA-DR was shown to be efficient from primary $\mathrm{T}$ cells and monocytes infected in cell culture [26], these molecules were less efficient than CD44 for capture of HIV from clinical samples [27, 28]. Other possibilities are intriguing. ICAM-1 increases the efficiency of HIV-1 infection [55] and could provide insights into specific forms of the virus. However, this work was done in cultured cell lines. Still, the efficiency of the isolation of HIV particles from patient samples using LFA-1 (CD18 /CD11a), CD63, ICAM-1 or HRS has not been experimentally assessed. For now, CD44 appears to be the 
best choice for efficient capture of HIV from patient samples.

This represents the first time that success has been achieved in acquiring sequences from patient plasma samples containing viral loads below 48 copies/ml without applying ultracentrifugation to the plasma sample — a step that can degrade the viral material. The virus isolated from each patient was unique, as demonstrated by the separate clusters in the phylogenetic trees and the high bootstrap values, thus diminishing the possibility of contamination.

Further analysis of the data showed that plasma viral forms are derived from more than one source. This finding supports the theory that residual viremia is derived not only from resting $\mathrm{CD} 4+\mathrm{T}$ cells but also from another reservoir [7].

Most monocytes have a low expression of CD16 and CCR5 and have been shown not to harbor HIV-1. In contrast, the relatively smaller proportion of monocytes that are CD14+ CD16+, which make up only $5-15 \%$ of the monocyte population, express CCR5 to a much higher degree [56]. Ellery et al. [57], have shown that monocytes that express CD16 are much more permissive to HIV-1 infection in vivo and in vitro.

In two of the patients, specific cell types (CD4+ T cells and $\mathrm{CD} 14+\mathrm{CD} 16+$ monocytes) were examined as potential viral sources. An evolutionary history was then reconstructed using nucleotide sequences from plasma, CD4+ T cells and monocytes. HIV-1 env plasma sequences were shown to be more related to provirus sequences present in CD14+ CD16+ monocytes than in resting CD4+ T cells. This agrees with data suggesting that HIV-1 derived from a cell of a myeloid lineage predominates in the plasma of patients receiving effective antiretroviral therapy [23] and with the above-cited findings of Ellery et al. [57]. None of the viral forms from the plasma of these two patients had disabling mutations. Other unsampled cell populations could be the source of the plasma virus, including tissue-associated macrophages. The viral forms in a majority of the patients in the plasma sequences study were macrophage tropic or dual tropic.

Several of the positive samples had only one viral form. This could be due to resampling and makes the lack of diversity suspect. In this study, with samples below quantification levels, it is possible that very few virions were present, making the problem of resampling more acute. Kearney et al. [58] introduced a method for obtaining sequences from single virions. This method, however, began with sample dilution from a higher, measurable viral load.

Subsequent studies are required to determine the processes involved in viral replication and viral production in infected individuals when the plasma levels are below 48 copies/ml. This information can give the scientific and clinical community the opportunity to develop new approaches to create better eradication strategies.

In conclusion, the developed genotypic assay showed success in the characterization of HAART-suppressed plasma HIV-1 RNA in half of the patients while reducing the amount of sample needed and the processing time. This method can be used to illuminate the residual viral forms in patients with low levels of virus and those classified as elite controllers.

Acknowledgments This work would not have been possible without the HIV+ individuals who voluntarily and kindly donated their time and samples for the benefit of society in general. Thanks to Dr. Grisell Tirado for contributions in the discussion of the study. Also, thanks to Mr. Pablo Lopez and the AIDS Research Program at Ponce School of Medicine (PSM) for flow cytometry cell sorting and determination of the plasma viral loads. The work was financially supported by the National Institutes of Health grants National Institute of General Medical Sciences- Minority Biomedical Research Support (NIGMS-MBRS) (S06-GM008239) (to E. Lorenzo) and Research Centers in Minority Institutions (RCMI) (2G12RR00305020) (PSM Molecular Biology Core).

Open Access This article is distributed under the terms of the Creative Commons Attribution Noncommercial License which permits any noncommercial use, distribution, and reproduction in any medium, provided the original author(s) and source are credited.

\section{References}

1. Finzi D, Blankson J, Siliciano JD et al (1999) Latent infection of CD4 $+\mathrm{T}$ cells provides a mechanism for lifelong persistence of HIV-1, even in patients on effective combination therapy. Nat Med 5:512-517

2. Gunthard HF, Frost SD, Leigh-Brown AJ et al (1999) Evolution of envelope sequences of human immunodeficiency virus type 1 in cellular reservoirs in the setting of potent antiviral therapy. J Virol 73:9404-9412

3. Ibanez A, Puig T, Elias J et al (1999) Quantification of integrated and total HIV-1 DNA after long-term highly active antiretroviral therapy in HIV-1-infected patients. AIDS 13:1045-1049

4. Pomerantz RJ (2001) Residual HIV-1 infection during antiretroviral therapy: the challenge or viral persistence. AIDS 15:12011211

5. Pomerantz RJ (2003) Reservoirs, sanctuaries, and residual disease: the hiding spots of HIV-1. HIV Clin Trials 4:137-143

6. Pomerantz RJ (2004) Ludwik Hirszfeld Memorial Lecture: HIV-1 reservoirs: major molecular obstacles to viral eradication. Arch Immunol Ther Exp (Warsz) 52:297-306

7. Shen L, Siliciano RF (2008) Viral reservoirs, residual viremia, and the potential of highly active antiretroviral therapy to eradicate HIV infection. J Allergy Clin Immunol 122:22-28

8. Chun TW, Stuyver L, Mizell SB et al (1997) Presence of an inducible HIV-1 latent reservoir during highly active antiretroviral therapy. Proc Natl Acad Sci USA 94(24):13193-13197

9. Finzi D, Hermankova M, Pierson T et al (1997) Identification of a reservoir for HIV-1 in patients on highly active antiretroviral therapy. Science 278:1295-1300

10. Wong JK, Hezareh M, Gunthard HF et al (1997) Recovery of replication-competent HIV despite prolonged suppression of plasma viremia. Science 278:1291-1295 
11. Hermankova M, Ray SC, Ruff C et al (2001) HIV-1 drug resistance profiles in children and adults with viral load of $<50$ copies/ml receiving combination therapy. JAMA 286:196-207

12. Dornadula G, Zhang H, VanUitert B et al (1999) Residual HIV-1 RNA in blood plasma of patients taking suppressive highly active antiretroviral therapy. JAMA 282:1627-1632

13. Han Y, Wind-Rotolo M, Yang HC, Siliciano JD, Siliciano RF (2007) Experimental approaches to the study of HIV-1 latency. Nat Rev Microbiol 5:95-106

14. Kieffer TL, Finucane MM, Nettles RE et al (2004) Genotypic analysis of HIV-1 drug resistance at the limit of detection: virus production without evolution in treated adults with undetectable HIV loads. J Infect Dis 189:1452-1465

15. Martinez-Picado J, DePasquale MP, Kartsonis N et al (2000) Antiretroviral resistance during successful therapy of HIV type 1 infection. Proc Natl Acad Sci USA 97:10948-10953

16. Natarajan V, Bosche M, Metcalf JA et al (1999) HIV-1 replication in patients with undetectable plasma virus receiving HAART: highly active antiretroviral therapy. Lancet 353:119-120

17. Nettles RE, Kieffer TL, Kwon P et al (2005) Intermittent HIV-1 viremia (Blips) and drug resistance in patients receiving HAART. JAMA 293:817-829

18. Sahu GK, Paar D, Frost SD et al (2009) Low-level plasma HIVs in patients on prolonged suppressive highly active antiretroviral therapy are produced mostly by cells other than CD4 T-cells. J Med Virol 81:9-15

19. Tobin NH, Learn GH, Holte SE et al (2005) Evidence that lowlevel viremias during effective highly active antiretroviral therapy result from two processes: expression of archival virus and replication of virus. J Virol 79:9625-9634

20. Finzi D, Plaeger SF, Dieffenbach CW (2006) Defective virus drives human immunodeficiency virus infection, persistence, and pathogenesis. Clin Vaccine Immunol 13:715-721

21. Kim H, Perelson AS (2006) Viral and latent reservoir persistence in HIV-1-infected patients on therapy. PLoS Comp Biol 2:12321247

22. Palmer S, Maldarelli F, Wiegand A et al (2008) Low-level viremia persists for at least 7 years in patients on suppressive antiretroviral therapy. Proc Natl Acad Sci USA 105:3879-3884

23. Bailey JR, Sedaghat AR, Kieffer T et al (2006) Residual human immunodeficiency virus type 1 viremia in some patients of antiretroviral therapy is dominated by a small number of invariant clones rarely found in circulating CD4+ T cells. J Virol 80:64416457

24. McClernon DR, Ramsey E, St Clair E (2007) Magnetic silica extraction for low-level human immunodeficiency virus type 1 genotyping. J Clin Microbiol 45:572-574

25. Tremblay MJ, Fortin JF, Cantin R (1998) The acquisition of hostencode proteins be nascent HIV-1. Immunol Today 189:346-351

26. Lawn SD, Roberts BD, Griffin GE et al (2000) Cellular compartments of human immunodeficiency virus type 1 replication in vivo: determination by presence of virion-associated host proteins and impact of opportunistic infection. J Virol 74:139-145

27. Lawn SD, Butera ST (2000) Incorporation of HLA-DR into the envelope of human immunodeficiency virus type 1 in vivo: correlation with stage of disease and presence of opportunistic infection. J Virol 74:10256-10259

28. Toossi Z, Mayanja-Kizza H, Lawn SD (2007) Dynamic variation in the cellular origin of HIV type 1 during treatment of tuberculosis in dually infected subjects. AIDS Res Hum Retrovirus 23:93-100

29. Lupo LD, Butera ST (2004) Application of $\mu$ MACS Streptavidin MicroBeads for the analysis of HIV-1 directly from the patient plasma. MACS \& More 8:16-19

30. Liao HX, Miller SE, Jones DM, Haynes BF (1996) Co-localization of CD44 expression with HIV budding in HIV-infected cells.
Conference on Advances in AIDS Vaccine Development; National Cooperative Vaccine Development Groups for AIDS. Meeting. Conf Adv AIDS Vaccine Dev Natl Coop Vaccine Dev Groups AIDS Meet 8th 1996 Bethesda, Md. 169

31. Suyama M, Daikoku E, Goto T et al (2009) Reactivation from latency displays HIV particle budding at plasma membrane, accompanying CD44 upregulation and recruitment. Retrovirology 6:63

32. Ott DE (1997) Cellular proteins in HIV virions. Red Med Virol 7:167-180

33. Terry VH, Johnston IC, Spina CA (2009) CD44 microbeads accelerate HIV-1 infection in T cells. Virology 388:294-304

34. Belair M, Dovat M, Foley B et al (2009) The polymorphic nature of HIV type 1 env V4 affects the patterns of potential N-glycosylation sites in proviral DNA at the intrahost level. AIDS Res Hum Retrovir 25(2):199-206

35. Castro E, Bélair M, Rizzardi GP et al (2008) Independent evolution of hypervariable regions of HIV-1 gp120: V4 as a swarm of N-Linked glycosylation variants. AIDS Res Hum Retroviruses 24(1):106-113

36. Lorenzo E, Herrera RJ, Lai S, Fischl MA, Hill MD (1996) The Tat and C2-V3 envelope genes in the molecular epidemiology of human immunodeficiency virus-1. Virology 221:310-317

37. Lorenzo E, Collins T, Fisher E, Herrera RJ (2001) The use of tat and env sequences from human immunodeficiency virus 1 in phylogenetic epidemiological studies. Electrophoresis 22:438-444

38. Hill MD, Lorenzo E, Kumar A et al (2004) Changes in the human immunodeficiency virus $\mathrm{V} 3$ region that correspond with disease progression: a meta-analysis. Virus Res 106(1):27-33

39. Lorenzo E, Colon MC, Almodovar S et al (2004) Influence of CD4+ T cell counts on viral evolution in HIV-infected individuals undergoing suppressive HAART. Virology 330(1):116-126

40. Rouet F, Chaix ML, Nerrienet E et al (2007) Impact of HIV-1 genetic diversity on plasma HIV-1 RNA Quantification: usefulness of the Agence Nationale de Recherches sur le SIDA second-generation long terminal repeat-based real-time reverse transcriptase polymerase chain reaction test. J Acquir Immune Defic Syndr 45:380-388

41. Berg ES, Olaisen B (1994) Hybrid PCR sequencing: sequencing of PCR products using a universal primer. Biotechniques 17(5):896-901

42. Thompson JD, Higgins DG, Gibson TJ (1994) CLUSTAL W: improving the sensitivity of progressive multiple sequence alignment through sequence weighting, position-specific gap penalties and weight matrix choice. Nucleic Acids Res 22(22):4673-4680

43. Higgins DG, Thompson JD, Gibson TJ (1996) Using CLUSTAL for multiple sequence alignments. Methods Enzymol 266:383402

44. Hall TA (1999) BioEdit: a user-friendly biological sequence alignment editor and analysis program for Windows 95/98/NT. Nucleic Acids Symp Ser 41:95-98

45. Tamura K, Dudley J, Nei M, Kumar S (2007) MEGA4: molecular evolutionary genetics analysis (MEGA) software version 4.0. Mol Biol Evol 24:1596-1599

46. Kimura M (1980) A simple method for estimating evolutionary rate of base substitutions through comparative studies of nucleotide sequences. J Mol Evol 16:111-120

47. Felsenstein J (1985) Confidence limits on phylogenies: an approach using the bootstrap. Evolution 39:783-791

48. Saitou N, Nei M (1987) The neighbor-joining method: a new method for reconstructing phylogenetic trees. Mol Biol Evol 4:406-425

49. Kuiken C, Foley B, Hahn B et al (2001) HIV sequence compendium 2001. Theoretical Biology and Biophysics Group. Los Alamos National Laboratory, Los Alamos 
50. Jensen MA, Li FS, van 't Wout $A B$ et al (2003) Improved coreceptor usage prediction and genotypic monitoring of R5-to$\mathrm{X} 4$ transition by motif analysis of HIV-1 env V3 loop sequences. J Virol 77:13376-13388

51. Lorenzo E, Kumar R, Hill MD et al (2004) Genetic characterization of human immunodeficiency virus type 1 Tat before and after highly active antiretroviral therapy. AIDS Res Hum Retrovir 20(10): $1108-1112$

52. Ziegler-Heitbrock L (2007) The CD14+ CD16+ blood monocytes: their role in infection and inflammation. J Leukoc Biol 81:1-9

53. Miura T, Brumme CJ, Brockman MA et al (2009) HLA-associated viral mutations are common in human immunodeficiency virus type 1 elite controllers. J Virol 83(7):3407-3412

54. Stemenkovic I, Aruffo A, Amiot M, Seed B (1989) A lymphocyte molecule implicated in lymph node homing is a member of the cartilage link protein family. Cell 56:1057-1062
55. Bounou S, Leclerc JE, Tremblay MJ (2002) Presence of host ICAM-1 in laboratory and clinical strains of human immunodeficiency virus type 1 increases virus infectivity and CD4(+)-T-cell depletion in human lymphoid tissue, a major site of replication in vivo. J Virol 76:1004-1014

56. Weber C, Belge KU, Von-Hundelshausen P et al (2000) Differential chemokine receptor expression and function in human monocytes subpopulation. J Leukoc Biol 67:699-704

57. Ellery PJ, Tippett E, Chiu YL et al (2007) The CD16+ monocyte subset is more permissive to infection and preferentially harbors HIV-1 in vivo. J Immunol 178:6581-6589

58. Kearney M, Palmer S, Maldarelli F et al (2008) Frequent polymorphism at drug resistance sites in HIV-1 protease and reverse transcriptase. AIDS 22:497-501 